\title{
The Ghawa Syndrome in Kuwaiti-Arabic Verbs
}

\author{
Hanan A. Taqi \\ The English Department, College of Basic Education, Ardhiya, Kuwait. \\ hanan.taqi@gmail.com
}

\begin{abstract}
The "Ghawa Syndrome" is a well-known linguistic phenomenon in the Arabian Gulf. In this phenomenon, the first open syllabus of a word is re-syllabified. The current study investigates the occurrence of this linguistic feature in Kuwaiti verbs within the variation of accents in the speech of two ethnic groups (Najdis and Ajamis) and three generations. The ethnicity factor was believed to play a major role in the linguistic feature under investigation due to their varying social and economic status. 48 Kuwaiti individuals represented the two investigated ethnicities and three age groups (chosen according to relevant milestones in the history of Kuwait), and with an equal number of males and females participating in data collection. Three different techniques of data collection were utilized (picture-naming, map task, interview \& questionnaires). The results reflected an increase in the use of the Ghawa Syndrome across generations in the Ajami group, while the Najdi dialect was rather stable. This linguistic familiarity seems to affect the two ethnicities, bringing them closer to each other.
\end{abstract}

Indexing terms/Keywords : Dialect, Accent, Kuwaiti, Najdi, Ajami, Adaptation, Language Shift, Sociophonetics

Subject Classification : Comparative Linguistics

Language : English

Date of Submission : 2018-01-17

Date of Acceptance : 2018-02-20

Date of Publication : 2018-02-28

ISSN : 2348-3024

Volume : 09 Issue : 01

Journal : Journal Of Advances In Linguistics

Publisher : CIRWORLD

Website : https://cirworld.com

This work is licensed under a Creative Commons Attribution 4.0 International License. 


\section{Introduction}

Sociophonetics is a fairly new area of phonetics, addressed by many scholars (Hay 2006, Haeri 2000, Foulkes \& Docherty 2006). It is well-defined as the field of linguistics that inspects "variable aspects of phonetic or phonological structure in which alternative forms correlate with social factors" (Foulkes and Docherty, 2006:411). The belief in the importance of social construction in inducing phonetic variability and variation has been reinforced by most studies conducted within the field of sociolinguistics. The most affective variables on the use of specific phonetic features, that are recognized as having systematic forms which correlate with certain social classifications, are mainly ethnicity, gender, age, social class and geographical origin (Tagliamonte, 2006).

The purpose of this study is delivering a phonetic description of vocalic variation taking place amid two Kuwaiti ethnic groups, highlighting the effect of the social factors of age, gender and ethnicity. Usually, sociophonetic variation is believed to be a signal of the social group or the community of the speaker. The use of one phonetic feature over another, is an indication of which group or community the speaker belongs to. In a study conducted by Labov (1966) on phonetic variation in New York city, Labov was able to show that higher social groups tend to use the approximant/ג/ in post-vocalic position more than the lower social groups. Since Labovs 1966 study, many studies followed investigating the association of certain linguistic features and social status. Comparatively, very few of which have been conducted on Arabic dialects, and even less on Kuwaiti. In the context of Arabic sociolinguistics, while some variables are very common, other variables are less common. The Ghawa Syndrome in verbs has received little attention from Arabic sociolinguists.

The first part of the current study will provide information on Kuwait and the Kuwaiti sociolinguistic context. The analysis of the social factors affecting language variation will be demonstrated, along with a review of the key features of the Kuwaiti vowels. Furthermore, the second part will cover the methodology utilized to collect and analyse data. Data collection depended on free and controlled environments to obtain a variety of information and insure reliability. Moreover, methods of analysis will be explored by utilising SPSS features. The results of the current investigation will be specified in detail and followed by the discussion of the results in light of the literature review. Finally, a conclusion will provide a summary of the findings, accompanied by a brief assessment of the topic and the methodology.

\section{Literature Review}

\subsection{Historical background}

Kuwait is a small country only $17.818 \mathrm{~km}^{2}$. According to the United Nations, the population of Kuwait is $4,169,164$ residents in 2018 , of which $30 \%$ are Kuwaitis (www.wolrdometers.info). Its neighbours are Iraq to the north and northwest, and Saudi-Arabia from the west and south. The east of Kuwait is lined by the Arabian Gulf (also known as the Persian Gulf). Across from the Gulf, facing Kuwait on the map, is Iran. These three neighbouring countries reflect the formation of the Kuwaiti society.

In the early $17^{\text {th }}$ century, Bani Khaled was the most dominant tribe in the Arabic peninsula, specifically in Kuwait. Abu-Hakima (1983) stated that the dominance of Bani-Khaled covered parts of Iraq, Kuwait and extended to Qatar in the south (p.3). in the mid-17 ${ }^{\text {th }}$ century, a tribe from the Saudi-Arabian land called "Najd" moved to Kuwait after passing Qatar and Bahrain. This tribe was called "Utub".

The Utub settled at the shores of Kuwait, after gaining permission from Bani-Khaled. Gradually, the tribes from Utub became powerful through their exceptional abilities in trading and commerce. In the late $18^{\text {th }}$ century, AlSabah family, descendants of the Utub, ruled Kuwait after being elected as rulers by the people of Kuwait. Sabah the first became the first prince of Kuwait.

Kuwait gained a reputation as being the land of opportunities because of its rapid economic flourish. This reputation quickly spread to the Gulf area and Iran. Soon, people from Saudi Arabia, Bahrain, Iraq and Iran started migrating to Kuwait. Hassan (2009) found that migration extended to the early $20^{\text {th }}$ century, when many Persian families settled in Kuwait (p.9).

The social interaction between the Arab and non-Arab population in Kuwait was mainly hindered by language. The status of the Persian migrants was highly affected by their language, in addition to their different Islamic 
sectarian beliefs. While most Arabs spoke in Arabic and were Sunni Muslims, the Persians mainly spoke in Persian and were Shiite Muslims.

The Persians were called Ajamis (lit. foreigners in Arabic) due to their language difference. During the early $20^{\text {th }}$ century, the Arabs and Ajamis rarely socialized. While most Arab families, including the Utubs, settled in an area called Jibla, the Persians largely settled in an area called Sharq, setting geographical boundaries in addition to the linguistic one. With the introduction of formal education in 1936, Arabic spread through Sharq, yet linguistic differences remained eminent. A good example of these linguistic differences is the word "sugar" /sukkar/, realized by the people of Jibla as [Jakir], and by the people of Sharq as [jikar]. Another example is the word "mother /omi:/, known to be realized as [jummə] by the people of Jibla, and [jumma:] by the people of Sharq.

Since becoming a state, Kuwait became a multinational country, hosting expatriates from around the world. Most expatriates were from Arab countries such as Egypt, Palestine and Syria. Non-Arab expatriates were mostly from India and the Philippines. The diversity in population allowed Kuwait to become a multilingual and multidialectal country. In spite of all linguistic differences, the grounds were set socially, politically and economically for the Utub's dialect to be considered the most dominant and prestigious.

\subsection{Language \& Prestige}

Trudgill (2009) noticed the importance of language prestige stating that "there are social preserves to achieve prestige or to appear correct" (p.74). While many studies emphasized the value of prestige through comparing the standard language with the vernacular (Holes 1983, Abu Haider 1989 amongst others), it has become clear that in most Arab communities, a specific vernacular would hold the most prestige. Therefore, the comparison between the prestige of the standard with the prestige of a dialect was minimized, as the most influential comparison was that between variations of dialects in a nation. Bassiouney (2009) found two main reasons to assume one dialect as being the most powerful. She found that socioeconomic power of the city over the suburbs as one reason. The other reason was the political power possessed by a social group (as is the case in the Gulf States). The more powerful the social group is, the more prestigious their dialect becomes.

Prestige is connected in some societies to ethnicity, which is a bond of group identification. Unlike identity, ethnicity is not a matter of choice; since its inherited, it could not be changed (Bassiouney, 2009:98). One of the best examples of the effect of ethnicity on language prestige is the case of Jordan. The socioeconomic events of Jordan shaped the linguistic platform. The Jordanian community consists mainly of Jordanians and Palestinians, who were forced to migrate to Jordan from major (economically and socially prestigious) cities in 1948 (Al-Wer, 1991). Linguistically, Jordan is divided into four main dialectal groups; namely, Bedouin Jordanian, rural Jordanian, urban Palestinian \& rural Palestinian (Bassiouney 2009:100). In 1970, the political development of Jorden started, bringing the rural Jordanian linguistic features power, and subsequently becoming a prominent symbol of the Jordanian identity (AI-Wer, 2007). An example of this change of power lies in the realization of [q] as [g], a main feature of rural Jordanian. Suleiman (2003:115) found that most male Palestinians, in 1970, reverted to the use of [g] instead of the urban [?]. However, once this confrontation between Jordanians and Palestinians ended, the urban Palestinian dialect assumed its place as a "symbol of modernity and education" (Bassiouney, 2009:101).

Linguistic change and its association to gender has been investigated widely by many linguists (Chambers, 1995; Haeri, 1997; Al-Wer, 1991 among others). Al-Wer (2005:631) found that gender was the most sophisticated social variable in sociolinguistics. Although men and women live in one society together, they seem to have different views of what is more prestigious and acceptable in a society. In his study on the women in Philadelphia, Labov (1966) found that women usually revert to the prestigious and innovative form of a language more than men. Labov believed that these findings "are not better than speculations" (p.304) as the role of genders differs by time and, social and cultural context. As the prestigious variety in the western society used to be reflected in the standard, Trudgill (2002:70) found that women tend to use the standard, and hence prestigious variety more often.

However, in the Arab world, prestige and standard are not normally interchangeable. It appears that the dialect used by the dominant group is normally considered the prestigious form in a society. Typically, Arab women do 
not think of a language as being standard or vernacular, they think of it in light of prestige. Al-Wer (2008) stated that whether standard or vernacular, Arab women tend to use the prestigious form.

In a study on the use of consonantal variables in Kuwaiti-Arabic, Taqi (2010) found that the Najdi dialect appeared to be the most prestigious dialect form, and a clear generational shift went towards the Najdi variety. As Najdis are the most prestigious socioeconomic ethnic group connected to the ruling power, the community (including Najdis) seem to preserve and aim to speak their dialect. The Ajami dialect, was a reflection of the Najdi dialect, since their dialectal form was the least prestigious - a reflection of the lowest social-scale position Ajamis held (Holes 2018:987).

In her study, Taqi (2010) interviewed 48 male and female participants from Najdi \& Ajami ethnic backgrounds. She found that the younger generation of Ajamis resembled the Najdi variant most. A clear and gradual transformation towards the Najdi dialect was shown by age which not only reflected the belief of Najdis as being "the real Kuwaitis" (p.226), but also the effect of the change of social networks, allowing young Ajamis to mix socially with the Najdis. As for gender, it was found that male participants used the Najdi variable more than female participants. It appeared that the social pressure to speak "Kuwaiti" or "not Kuwaiti" (p.226) formed more pressure on the men which might be "due to the increasing demand on the part of the male Ajamis to acquire local societal norms "which allows them to submerge in an all Kuwaiti community" (p.227).

\subsection{The Kuwaiti Arabic Vowels}

The vowels of Kuwaiti-Arabic have been long investigated by Johnston in 1967. Kuwaiti-Arabic includes eight vowels (long and short): /a, i, u, a:, e:, i:, o:, u:/. In addition, excluding /a/ in open-nonfinal syllables, /i/ is used adjacent to glottal $/ x, g, h, ?, h /$ and consonants $/ l, r, n$ / when the vowel of the following syllable is /a/ or /a:/ (Johnston, 1967:27). A good example might be the word /tisallam/ (he received) but/tisallimaw/. According to Holes (2018), labiles appear to have a more round-back effect on /i/ in the speech of the less educated, especially in the presence of a velar, thus /i/ would sound closer to a / $\mathrm{u}$ / as in words like /mukan/ (place) and /Jurbat/ (she drank). This would occur solely in open syllables. Moreover, /a:/ and /a:?/ are shortened in open syllables when occurring in final possession and not in vicinity to a guttural, an emphatic, /l/ or / $r$. When emphatics and gutturals (excluding $/ \mathrm{h} /$ ) are absent, Holes (2018) found that $/ \mathrm{a} /$ would be realized as $/ æ / \mathrm{or} / \varepsilon /$ as in the word /hæli/ (my family). As for long vowels, Holes (2018) found /a:/ to be more retracted, especially in the presence of an emphatic or $/ x, 1, r, g /$, as in the words [sa:l] (it flowed) and [ga:l] (he said).

When it comes to diphthongs, /aw/ seems to be a very common diphthong of Kuwaiti-Arabic, which is normally reduced to /a:/ when being preceded with a heavy syllable such as Cvv or CvC as in the word /ma:dzu:d/ (exists). In the verbs, /aw/ turns into /o:/ when suffixed, such as in the word /galaw/ (they said) as opposed to /ga:lo:li:/ (they told me).

While Holes (2018) identifies several syllable types utilized in Kuwaiti Arabic, he identifies the existence of the Ghawa Syndrome. This Najdi feature is based on CaCCv resyllabification. The sequence in this structure would generally be changed to CCVCC. The morphophonemic form depends on the dropping of /a/ in the first open syllable and the next vowel of the second open syllable is affected. Holes (2018) defines the term as being "the deletion of $/ a /$ in $\mathrm{CaC}$ non-final syllables where $C_{2}$ is guttural, and epenthesis of $/ a /$ after $C_{2}{ }^{\prime \prime}$, bringing the example of /nxala/ (palm) as opposed to standard Arabic /naxla/. Another example is from which the term has been taken, the word /gahwa/ (coffee) would be realized as /ghawa/.

The current study will investigate the occurrence of the Ghawa Syndrome in the Najdi dialect in verbs. The investigation aims at answering the following questions,

1. When are verbs affected by the Ghawa Syndrome?

2. What is the effect of ethnicity on the use of the Ghawa Syndrome?

3. What is the effect of gender on the use of the Ghawa Syndrome? 
4. What is the effect of age on the use of the Ghawa Syndrome?

\section{Methodology}

The current study was carried out in the State of Kuwait. The methodology for this study is two folded. It investigates phonological variation experimentally, and studies independent variables such as ethnicity, gender and age theoretically. Both investigations would be correlated in order to find the effect of demographic variables on the features of speech.

Considering that there are very few phonological studies on Kuwaiti Arabic, the investigation started with a pilot study consisting of 15 speakers (6 male and 9 female Kuwaitis), aged 22-60. This study helped the researcher identify the main linguistic features of Kuwaiti Arabic (KA hereafter), and the dialectal differences between the two ethnic groups under investigation. The outcome of the pilot study directed the researcher towards the investigation of the Ghawa Syndrome in verbs.

The sampling method in this study was mainly inspired by Al-Wer (1991) who used age, gender and educational background as criteria to choose her PhD thesis sample. The current study involved 48 informants, 24 males and 24 females. The participants belonged to 3 age groups, chosen specifically to resemble historical (thus social) events in Kuwait. The first age group was between 50-60 years old, which lived their youth prior to the exploration of oil, which led to huge educational and economical changes. The second group where in their 30s and 40s, this generation experienced the flourish of Kuwait's economy after the exploration of oil, leading to major educational and social changes. The third generation was chosen in ages between 18 and 22, resembling the generation that has lived a stable era, economically and socially.

The researcher employed three approaches to record data; and obtained qualitative and quantitative data through the distribution and supervision of a questionnaire. First, 20 to 30 minutes of free-talk was recorded to obtain the most natural form of speech possible. Second, a PowerPoint presentation with 48 slides was followed. The slides contained pictures that elicited nouns and verbs the informants were required to identify in KA. The last technique included a map with names of streets and buildings. The informants were required to describe the direction of getting from one place to another, pronouncing the names of buildings and streets in the process. This technique was adapted from discourse analysis methods (Anderson et al. 1991, Miller \& Weinert 1998, Brown 2000) and helped build enthusiasm during the interview. A questionnaire was also designed based on a questionnaire established by Ohannessian, Ferguson, and Polome 1975. This choice was made based on the striking similarity between their study and the sociophonetic situation in Kuwait. The questionnaire included demographical questions such as age, gender, and level of education; it also comprised questions about the linguistic variety in Kuwait, and how acceptable it is to use certain languages/dialects.

\section{Results}

It is essential to begin with the identification of the vowels that comprise the Ghawa Syndrome in verb forms, and the forms in which this feature typically would occur. It was found that in most literature, the Ghawa syndrome is identified as the verbs that follow the CaCa- or CaCi- initial verb pattern in Standard Arabic (SA hereafter), which are different in their realisation in KA. Yet, linguists, such as Holes (2015:42) believed that these words would be defined in KA in the form of CCa-. A good example would be the words [qahwa] (coffee), which was defined as /ghawa/ in KA (which is where the term originated from). However, being a Kuwaiti, the researcher had reason to believe that there was a vowel that preceded the first consonant. Since the researcher felt that the Ghawa Syndrome actually

started with /I/, a screen capture from Praat of the word [Isma\{at] (SA /sami אat/, she heard) taken. Figure 1 below clearly shows that there is a short vowel preceding the initial consonant. The formants measurements of the vowel reflect an $\mathrm{F} 1$ of $451 \mathrm{~Hz}$ and an F2 of $1959 \mathrm{~Hz}$, which closely resemble /I/ according to Delattre (1964). 


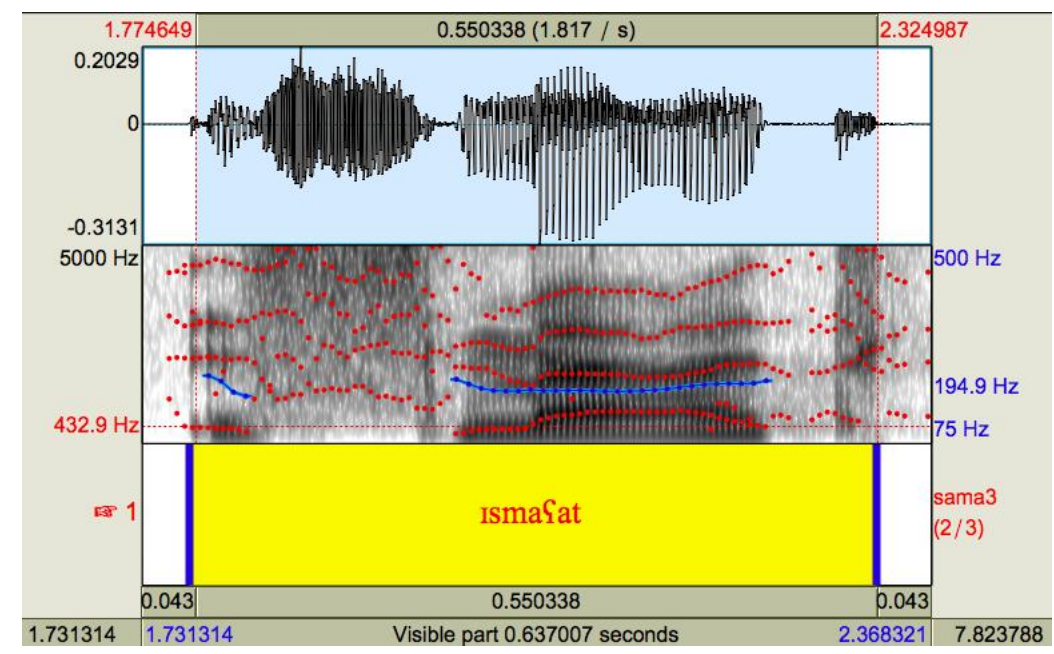

Fig 1 The word [Ismafat] (she heard) in KA

The prefixes of the following two past tense verb derivatives are the focus of this study:

1. Past $3^{\text {rd }}$ person singular feminine

2. Past $3^{\text {rd }}$ person plural (used in KA for both genders)

The structure of the two verb tenses analysed in this study also follows a CaCa- or CaCi- structure in SA. However, in the speech of Najdis and Ajamis, they take two different forms. This study will analyse the $3^{\text {rd }}$ past singular feminine and the $3^{\text {rd }}$ past plural (masculine and feminine in KA). Table 1 illustrates the tenses observed in this section in SA, Najdi and Ajami speech.

\begin{tabular}{|c|c|c|c|}
\hline Verb tenses & Realisation in SA & $\begin{array}{c}\text { Realisation in } \\
\text { Najdi }\end{array}$ & $\begin{array}{c}\text { Realisation in } \\
\text { Ajami }\end{array}$ \\
\hline $\begin{array}{l}3^{\text {rd }} \text { past singular feminine } \\
\text { (she ran) } \\
\text { (she typed) }\end{array}$ & $\begin{array}{l}\text { /rakaðat/ } \\
\text { /t'aba؟at/ }\end{array}$ & $\begin{array}{l}\text { [Irkiðat] } \\
\text { [It'baSat] }\end{array}$ & $\begin{array}{l}\text { [rikðat] } \\
\text { [t'ibৎat] }\end{array}$ \\
\hline $\begin{array}{l}3^{\text {rd }} \text { past plural } \\
\text { (they played) } \\
\text { (they typed) }\end{array}$ & $\begin{array}{l}\text { /laSabu:/ } \\
\text { /t'abaSu:/ }\end{array}$ & $\begin{array}{l}\text { [IlSibaw] } \\
\text { [It'baSaw] }\end{array}$ & $\begin{array}{l}\text { [lisbaw] } \\
\text { [t'ibكaw] }\end{array}$ \\
\hline
\end{tabular}

Table 1 Illustration of iCCi- and iCCa- verb structure

It was found that Ghawa Syndrome in verbs does not occur under the following conditions:

1. When the verb skeleton starts with a glottal stop, it is often deleted in KA. It should be noted that in many nouns the glottal stop is replaced by [a] However, unlike nouns, verbs in KA that have a glottal stop initially in its root are realised with the consonant following the glottal stop. In addition, the verb maintains the CaCa- structure. For example the root '? $\mathrm{kl}$ ' (to eat), the past tense ${ }^{3 r d}$ singular (feminine in SA) Rakalat/ would be realised by both ethnic groups as [kalat].

2. When the second consonant in the verb structure is geminate. The verb structure in SA is CaCC-. Gemination affects verb derivatives in SA from CaCa- to CaCCa-; for example /samafat/ (she heard $3^{\text {rd }}$ past tense feminine) as opposed to /wallat/ (she left $3^{\text {rd }}$ past tense feminine). It also affects the verb's structure in KA. A good illustration of that is the $3^{\text {rd }}$ past tense singular feminine /Vannat/ (she sang) 
which is realised in KA as [Yannat]; in the past tense $3^{\text {rd }}$ plural (feminine \& masculine) in SA / Vannu:/ would be realised by both groups as [Yannaw].

Since neither the Najdi nor the Ajami groups use the SA realisation in the above verb derivatives (in SA the form is $\mathrm{CaCa}$ - and $\mathrm{CaCi}-$ ), in the phonological analytical framework I am drawing on, one form must be considered to be the original (the input), and the other form would be considered the changed form (the output). The model for comparison chosen for these verbs is the Najdi realisation, which reflects the Ghawa Syndrome. Either dialect would have served as a good basis for comparison, but since the Najdi dialect is considered by most Kuwaitis to be the KA dialect, it was chosen as the model derivative of these two verb forms. The variation in the pattern of these two verb derivatives follows the following forms: ICCa- and ICCi- (Najdi) and CiCC- (Ajami).

Only verbs which follow a $\mathrm{CaCa}$ - structure in $\mathrm{SA}$ (not $\mathrm{PaCaC}$ - or $\mathrm{CaCC}$ - for example) were investigated in this study. Words following the two structures mentioned above were eliminated from the interview data analysis as they were avoided in the controlled data, reflecting the similarity found in both data sets. Najdis categorically realise these verb forms as ICCa- and ICCi-. Although this confirms that this syllable structure of the verb correlates with ethnic background, the statistical description of the Ajami versus the Najdi realisations on its own is not informative enough. Therefore, this study will focus on analysing gender and age as social factors influencing the realisation of the Ghawa Syndrome and will only refer to ethnicity when needed.

\subsection{Data and statistics for Ghawa Syndrome verb form}

Figure 2 represents both controlled and interview data. The total number of tokens represented from the controlled data is 960 (20 tokens per speaker). On the other hand, the total number of tokens collected in the interview data is 864 (an average of 18 tokens per speaker). Figure 2 displays the use of CiCC-, where the missing percentages are for the use of Ghawa Syndrome verb form. The Najdi group were not presented as they categorically use the verbs investigated in the Ghawa Syndrome verb pattern. Figure 2, therefore, represents the Ajami informants grouped in terms of gender and age. All analyses in this chapter will view data from both controlled and interview sources as before. The two-way mixed factorial ANOVA (age by gender) was calculated on the mean of CiCC- verb structure use values. Table (2) below shows the significance of the social factors independently and when interacting with each other in the realisation of Ghawa Syndrome verb structure as CiCC- at the level. As such, each social variable is investigated separately and when interacting with each other.

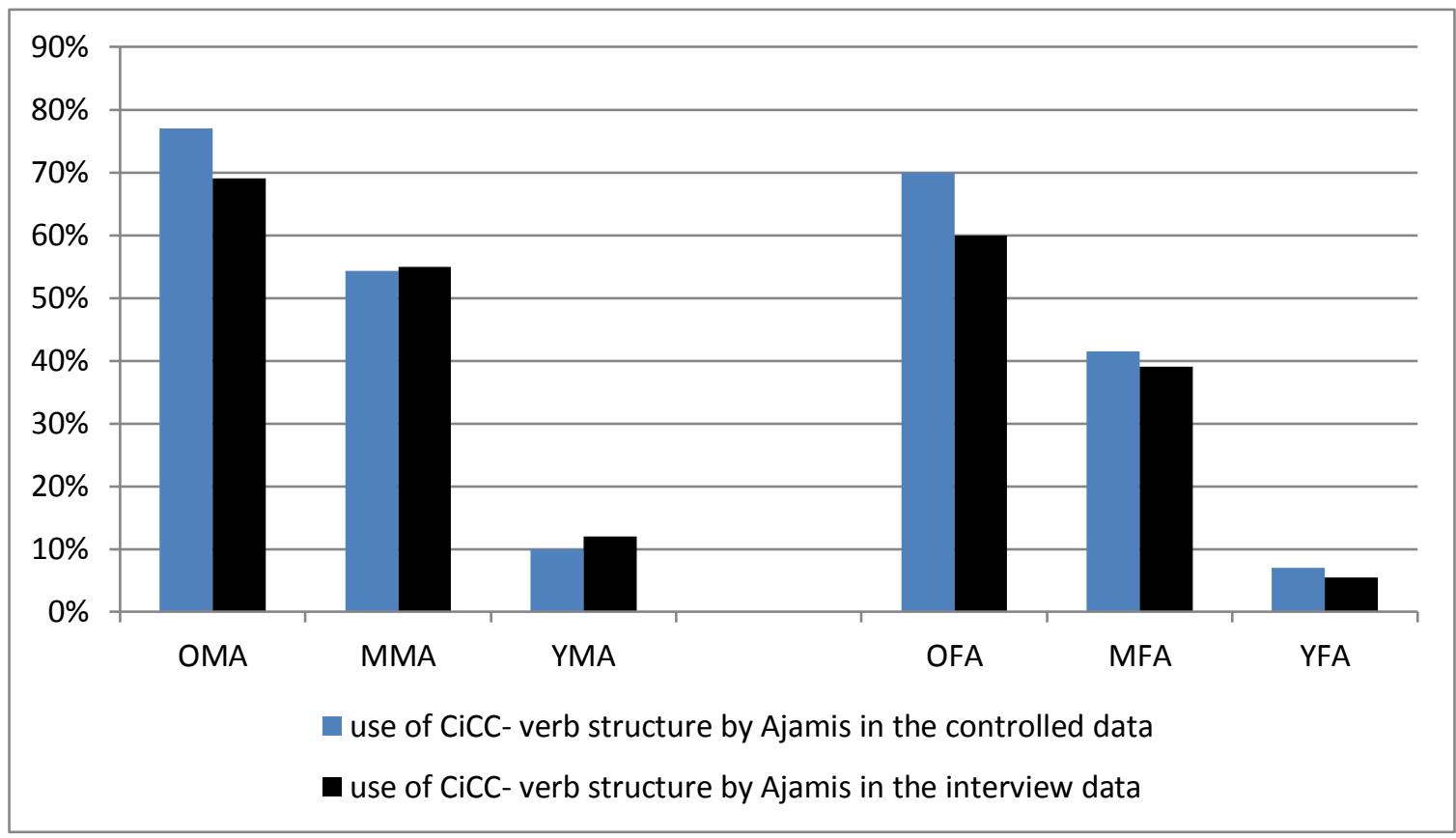

Fig 2 The CiCC- realisation in the speech of Ajamis by gender and age* 
*the missing percentages are of the Ghawa Syndrome verb form realisation

Table 2 Significance of social variables in the realisation of CiCC- initial verb form by Ajamis

\begin{tabular}{|c|c|c|c|c|c|c|}
\hline Source & $\begin{array}{l}\text { Dependent } \\
\text { Variable }\end{array}$ & $\begin{array}{l}\text { Type III Sum } \\
\text { of Squares }\end{array}$ & $d f$ & $\begin{array}{l}\text { Mean } \\
\text { Square }\end{array}$ & $\mathrm{F}$ & Sig. \\
\hline \multirow[t]{2}{*}{$\begin{array}{l}\text { Corrected } \\
\text { Model }\end{array}$} & controlled data & $\begin{array}{r}19726.000(a \\
)\end{array}$ & 5 & 3945.200 & 61.008 & .000 \\
\hline & interview data & $\begin{array}{r}\text { 13112.000(b } \\
\text { ) }\end{array}$ & 5 & 2622.400 & 4495.543 & .000 \\
\hline \multirow[t]{2}{*}{ Intercept } & controlled data & 49686.000 & 1 & 49686.000 & 768.340 & .000 \\
\hline & interview data & 7141.500 & 1 & 7141.500 & 12242.571 & .000 \\
\hline \multirow[t]{2}{*}{ Gender } & controlled data & 912.667 & 1 & 912.667 & .459 & .505 \\
\hline & interview data & 7141.500 & 1 & 7141.500 & 1.185 & .288 \\
\hline \multirow[t]{2}{*}{ Age } & controlled data & 18244.000 & 2 & 9122.000 & 141.062 & .000 \\
\hline & interview data & 2985.250 & 2 & 1492.625 & 2558.786 & .000 \\
\hline \multirow[t]{2}{*}{ gender * age } & controlled data & 569.333 & 2 & 284.667 & 4.402 & .028 \\
\hline & interview data & 2985.250 & 2 & 1492.625 & 8.786 & .001 \\
\hline \multirow[t]{2}{*}{ Error } & controlled data & 1164.000 & 18 & 64.667 & & \\
\hline & interview data & 10.500 & 18 & .583 & & \\
\hline \multirow[t]{2}{*}{ Total } & controlled data & 70576.000 & 24 & & & \\
\hline & interview data & 20264.000 & 24 & & & \\
\hline \multirow[t]{2}{*}{ Corrected Total } & controlled data & 20890.000 & 23 & & & \\
\hline & interview data & 13122.500 & 23 & & & \\
\hline
\end{tabular}

i. Ghawa Syndrome verb structure realisation by age

Age plays a major role in the use of the Ghawa Syndrome verb form. A one-way ANOVA (age) on the mean of CiCC- verb form use (as opposed to the Najdi form) results show that $F(2.23)=141.062, p<0.01$ in the controlled data, and $F(2.23)=2558.786, p<0.01$ in the interview data (where $p=0.05$ level). It is clear from Figure 2 above that the old Ajamis use the Ghawa Syndrome verb form the least, while the young group use it the most. Table 3 shows the percentages of CiCC- verb structure use by age groups, where a sharp decline in the use of CiCCform is clear in the middle-aged and young informants' speech.

Table 3 Percentage of CiCC- initial verb structure use in the speech of Ajamis by age

\begin{tabular}{|l|c|c|c|}
\hline Data type & Old Ajamis & Middle-aged Ajamis & Young Ajamis \\
\hline Controlled data & $73.5 \%$ & $48 \%$ & $8.5 \%$ \\
\hline Interview data & $64.5 \%$ & $47 \%$ & $8.8 \%$ \\
\hline
\end{tabular}

This shows that the young Ajamis use Ghawa Syndrome verb form most similar to Najdis. It is also clear in Figure 2 that in both the old and middle-aged groups the Ghawa Syndrome verb form is used less in the controlled 
data than in the interview data. However, this difference does not affect the significance of the Ghawa Syndrome verb structure use in both ethnic groups.

ii. Ghawa Syndrome verb structure realisation by gender

Figure 2 shows that male Ajamis use the CiCC- verb form more than their female peers (Table 5 below). However, this difference is insignificant. A one-way ANOVA (gender) of the mean of CiCC- use results show that $F(1.23)=0.459, p=0.505$ in the controlled data, and $F(1.23)=1.185, p=0.288$ in the interview data. However, when age interacts with gender, the results are different. A two-way ANOVA (gender by age) on the mean of CiCC-realisation shows that $F(4.23)=4.402, p=0.028$ in the controlled data, and $F(4.23)=8.786, p=0.001$ in the interview data (where $p=0.05$ level). Thus, when gender and age interact, these social variables show a significant correlation with Ghawa Syndrome verb form realisation.

When taking a closer view, it is clear that significance, regarding the correlation of usage with social variables, are apparent in the old and middle-aged groups. Thus, female speakers from the old and middle-aged groups show more use of the Ghawa Syndrome verb structure than males. There is no significance in the realisation of Ghawa Syndrome verb form between genders in the young Ajamis group.

Table 4 Significance of Ghawa Syndrome realisation by age and gender in the Ajami group

\begin{tabular}{|l|l|r|r|r|r|r|}
\hline Old-aged & & \multicolumn{1}{c|}{$\begin{array}{c}\text { Sum of } \\
\text { Squares }\end{array}$} & $\mathrm{df}$ & Mean Square & \multicolumn{1}{c|}{$\mathrm{F}$} & \multicolumn{1}{c|}{ Sig. } \\
\hline controlled data & Between Groups & 98.000 & 1 & 98.000 & 16.391 & .015 \\
& Within Groups & 92.000 & 6 & 15.333 & & \\
& Total & 190.000 & 7 & & & \\
interview data & Between Groups & 171.125 & 1 & 171.125 & 117.343 & .000 \\
& Within Groups & 8.750 & 6 & 1.458 & & \\
& Total & 179.875 & 7 & & & \\
\hline
\end{tabular}

\begin{tabular}{|l|l|r|r|r|r|r|}
\hline Middle-aged & & \multicolumn{1}{c|}{$\begin{array}{c}\text { Sum of } \\
\text { Squares }\end{array}$} & df & Mean Square & \multicolumn{1}{c|}{ F } & \multicolumn{1}{c|}{ Sig. } \\
\hline controlled data & Between Groups & 325.125 & 1 & 325.125 & 23.293 & .003 \\
& Within Groups & 83.750 & 6 & 13.958 & & \\
& Total & 408.875 & 7 & & & \\
interview data & Between Groups & 561.125 & 1 & 561.125 & 708.789 & .000 \\
& Within Groups & 4.750 & 6 & .792 & & \\
& Total & 565.875 & 7 & & & \\
\hline
\end{tabular}

\begin{tabular}{|l|l|r|r|r|r|r|}
\hline Young group & & \multicolumn{1}{|c|}{$\begin{array}{c}\text { Sum of } \\
\text { Squares }\end{array}$} & df & Mean Square & F & \multicolumn{1}{|c|}{ Sig. } \\
\hline controlled data & Between Groups & 32.000 & 1 & 32.000 & .545 & .488 \\
& Within Groups & 352.000 & 6 & 58.667 & & \\
& Total & 384.000 & 7 & & & \\
interview data & Between Groups & 84.500 & 1 & 84.500 & 1.364 & .248 \\
& Within Groups & 33.000 & 6 & 5.500 & &
\end{tabular}


Table 5 below shows the percentages of CiCC- verb form use (where the missing percentages are for the Ghawa Syndrome verb form). The Table shows the percentages of the use of CiCC-initial verb forms in the speech of male and female Ajami speakers in general as well as in the speech of the males and females divided by age groups.

Table 5 The percentage of the use of CiCC- initial verb form by gender, and by age and gender

\begin{tabular}{|l|c|c|c|c|}
\hline Group & \multicolumn{2}{|c|}{ Controlled data } & \multicolumn{2}{c|}{ Interview data } \\
\hline Male Ajami & \multicolumn{2}{|c|}{$47 \%$} & \multicolumn{2}{c|}{$45.4 \%$} \\
\hline Female Ajami & \multicolumn{2}{|c|}{$39.5 \%$} & \multicolumn{2}{c|}{$34.8 \%$} \\
\hline \multirow{2}{*}{ Old Ajamis } & male & female & male & female \\
\cline { 2 - 5 } & $77 \%$ & $70 \%$ & $69 \%$ & 60 \\
\hline Middle-aged Ajamis & $54.3 \%$ & $41.5 \%$ & 55 & $39 \%$ \\
\hline Young Ajamis & $10 \%$ & $7 \%$ & $12 \%$ & $5.5 \%$ \\
\hline
\end{tabular}

\section{Discussion}

This examination concentrated on the connection of three social components (ethnicity, gender and age) and their relationship with various phonetic realizations of two Kuwaiti accents. It was discovered that ethnicity, which is connected to economic wellbeing, is a standout amongst the most essential social components corresponding with phonological variety. Trudgill (2000:45) found that in numerous nations, (for example, Ghana and Canada) "different ethnic groups [...] maintain their separateness and identity as much through language as anything else". The 'separateness' isn't just shown by various dialects, yet it is likewise demonstrated by various assortments of one dialect, as the circumstance explored between the two older ages of the two ethnic groups of informants in this investigation. In any case, the decision of talking a specific dialect of Kuwaiti was controlled by social impacts. Mazraani (1997:7) noted that "the dialect which has great prestige and that is recognized as a hallmark of local identity and pride in the community" is normally the speaker's target. Sidnell (1999:394) noticed that the decision of one accent as opposed to another depends on the assumption of power and the speaker's ability to be recognized as having a place within a specific group. It is clear that ethnicity in Kuwait has a direct association with societal position. The Najdi dialect in Kuwait is clearly the direction of the speech of many Ajamis. It is viewed as the esteemed dialect as it mirrors the financial and historical part Najdis play in Kuwait. Najdis recognize themselves as 'real Kuwaitis'.

The use of Ghawa Syndrome verb structure has been identified by Holes (1987) as CCi- in Bahraini Arabic. However, as some Gulf Arabic dialects have shown to be similar to Kuwaiti Arabic in verb structure (with the use of a CiC- verb structure in Bahrain being similar to that found in Ajami Kuwaiti), the researcher assumes that the initial verb form is ICCa- and ICCi- even in Bahraini Arabic. This is supported by Holes' (ibid) findings that Arabs in Bahrain use the Ghawa Syndrome forms, while the Baharna (Shiites of Bahrain) use the CiCC-forms which coincides with the situation in Kuwait. Holes found that the people of Bahrain, especially the educated, tend to use the Ghawa Syndrome verb form as it is believed to be the most prestigious (Arabic-derived dialects are accorded the highest status in Bahrain). In addition, when Arabs live in Baharna communities, they seldom change their use of Ghawa Syndrome verb structure; however, when the opposite is true the Baharna tend to use Ghawa Syndrome forms more often. This finding supports the assumption that the prestige of the Najdi dialect is probably one of the reasons why the Ghawa Syndrome verb form is spreading in KA.

The occurrence of the CiCC- verb form seems to be a phenomenon similar to that found in Jordanian Arabic. Al-Wer (2003) noted that the Jordanian $2^{\text {nd }}$ person plural suffix -ku may have merged with the Palestinian -kun to form the Ammani Suffix -kum, such as Jordanian [minku] (from you) which is realised by Palestinians as [minkun], while it is realised by Ammanis as [minkum]. Similarly, the SA initial verb form $\mathrm{CaCa}$ - and $\mathrm{CaCi}$ - may 
have merged with the Najdi verb structure to form the Ajami structure CiCC-. For example, SA /samaSat/ (she heard) is realised by Najdis as [Isma\{at], and by Ajamis as [simfat]. The Ajami form may have been affected by the SA form being more similar to SA, yet the vowel /I/ is used in the Najdi form, which reflects the influence of the Najdi dialect on the Ajami realisation of initial verb forms.

So as to comprehend the bearing of accent change, it is critical to assess the connection between the variations explored and their SA representation from one perspective, and the effect of Farsi (Ajami) which may have influenced the realization of the target verbs. Many researchers have explored the status of SA and vernacular of Arabic nations (Ibrahim 1986, Haider 1989, Abdul-Jawad 200 among others), a large portion of which could identify with the Kuwaiti dialectal situation. For instance, Ibrahim (1986) expressed that in spite of the fact that SA holds a specific level of prestige as it is connected to religious and taught environments, local vernaculars are the ones that hold the more grounded social prestige 'that matter to most individuals in life such as socioeconomic class'.

When the Najdi speakers were asked which verb form sounds like the KA realisation, [Ismifat] (she heard) or [sim\{at], they categorically chose [Ismi $\{a t]$. One old female Najdi commented 'but some Kuwaitis say [sim\{at],

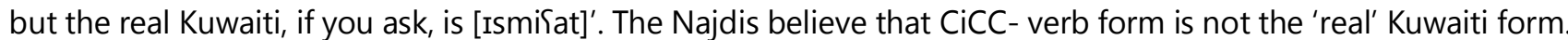
When asked who uses the CiCC- verb form, most Najdis did not know. A middle-aged male Najdi said 'I hear [simfat] a lot, but why do they say it like that? I don't know. Maybe they live with non-Kuwaitis'. Four out of twenty four (three middle-aged and one young females) Najdis believed that CiCC- is used by Ajamis. One young female Najdi said 'I have Ajami friends, and sometimes they say verbs like [sim\{at], the others [Najdis] don't say that, so I know that only Ajamis use these verbs [forms]'. All the Najdis participating in this study believe that the Ghawa Syndrome verb structure is, in fact, the Kuwaiti form. They also believe that the CiCCverb form is not used in SA or in other Gulf countries with the result that it should not be used as KA. A young male Najdi commented 'I hear verbs like [sim $\{a t]$ in the university sometimes and think why do they say that? They are Kuwaitis you know...I expect Kuwaitis to say verbs like [Ismißat] and the other ways [forms] don't sound right!'

The Najdi dialects' prestige, which is far ahead of SA, and the conceivable impact of Farsi (Ajami), can reveal insight into the direction of dialectal change in Kuwaiti Arabic. The diverse accents of Ajamis and Najdis in Kuwait appear to travel toward a path where most change is reflected in the discourse of Ajamis. This was characterized by Giles (1991:63-4) as 'convergence', which is "a strategy whereby individuals adapt to each other's communicative behaviours in terms of a wide range of linguistic/prosodic/non-vocalic features". Convergence is by all accounts heading towards the Ghawa Syndrome verb structure in KA, where the characteristics of Najdi becomes increasingly dominant through generations. In spite of the fact that when Giles' (1991) used the term 'convergence' he was referring to a two-way dialectal change. Yet, in KA, 'convergence' only appears to influence the Ajami community reflecting the prestige of the Najdis dialect and the weakness of the Ajami vernacular. Trudgill (1986:98) characterizes dialect levelling as the 'attrition' or 'reduction' of variations upheld by a constrained system structure. In Kuwait, Ajami CiCC-verb structure has appeared to be employed less by the second and third age groups of Ajami informants and replaced by the Najdi variations. This change of accent on the Ajami part reflects the inclination towards dialect levelling, where the result of this levelling is the continuing selection of Najdi variations. The change includes moving far from phonetic realizations that are believed to be socially unsatisfactory as they are generally disdained.

The Ajamis have different views of the Ghawa Syndrome verb form. Most old Ajamis believe that the two forms do not differ from the CiCC- form they tend to use. When asked which form was correct [sim[at] or [Ismi $\{a t$ ], one old male Ajami commented 'do people really think it's different? It's just the vowel that changed, right?' One old female Ajami disagreed 'It's not really 'correct' to say [sim\{at] because Kuwaitis say [Ismi middle-aged and young Ajamis all identified Ghawa Syndrome verb form as the Kuwaiti one. The Ajamis, who believe Ghawa Syndrome verb structure is the Kuwaiti form, were asked why then use the CiCC- verb structure? The answers differed. The old female Ajami said 'I'm used to saying [simfat], maybe because my older sisters and brothers say it, and I've learned a lot from them'. However, a middle-aged male Ajami said 'it's easier to say [sim\{at], [Ismißat] needs some effort and concentration'. This comment also seems to point to habit and the effect of the surrounding environment. Two young Ajamis believed that 'some words are always realised as 
[sim \{at] but not all verbs, so sometimes I say words 'wrong', but if I realise it, I correct it immediately'. One young male Ajami stated that 'I have many Ajami friends and it's sometimes a matter of repeating what they say, or using their words, so you say [sim\{at], then you think: why did I say that?' The surrounding environment seems to be the main factor affecting the use of Ghawa Syndrome verb forms, no matter how different their impact is.

Most studies investigating Arabic sociolinguistic variation found that female speakers use prestigious local dialect more than male Arab speakers (Abdel-Jawad 1981; Al-Wer 1991; Jassem 1993 among others). However, Taqi (2010) found that in the realization of consonants, Kuwaiti male speakers out preform the female speakers and leant towards the prestigious variety. The current study shows that the female speakers use the prestigious variant more than males. Gender alone has proven to be insignificant in the use of the Ghawa Syndrome verb structure in this investigation. Although the difference between male and female Ajamis in general was slight, female speakers used Ghawa Syndrome initial verb forms more than males. However, gender can be seen to play a role in the variation when it interacts with age, in which case, female speakers in the old and middle-aged groups use more Ghawa Syndrome forms than males. This significance is clear when a variable is judged by Ajamis as Kuwaiti and non-Kuwaiti, female Ajamis use the 'Kuwaiti' realisation more than the male speakers. A young female Ajami stated that 'I don't like to be labelled as Ajami or Arab, I'm Kuwaiti and my speech shows that', she added 'my parents say verbs like [sim\{at], it's normal among my parents, aunts and uncles, but outside our home, that is definitely wrong'.

The social contact amongst Najdis and youthful Ajamis has been on the expansion. All youthful Ajamis announced that they have friends from different ethnicities, and that they feel confident with their Kuwaiti as they trust it to be like the vernacular of their Najdi companions. Most youthful Ajamis trust their dialect is not the same as that of their folks and that it is 'more Kuwaiti'. Numerous young Najdis realize that their friends are Ajamis from their family names, and they all trust that their companions' vernacular is not the same as their own. Eckert (2000:210-211) found that amid young age, linguistic forms, and local (Najdi in the Kuwaiti society) are viewed as fundamental to 'adopt the style of a particular group', and in this way, pronounce the belonging to a certain group. The 'style' adopted in the Kuwaiti society is by all accounts the Najdi's as it is a reflection of the Kuwaiti identity. Bortoni-Ricardo (1985) found that the adjustment in social structure from an ' insulated' system, which comprises for the most part of families and neighbours, to an 'integrated' system, which is concerned with a more extensive social setting, which influences the dialect of migrants fundamentally. The general population who collaborate in an 'integrated' system would absorb features of the main dialect of the society. Generally, in the Kuwaiti society, the the Najdi variety is viewed as being the dialect of the society.

The Ghawa Syndrome verb structure is labelled 'Kuwaiti' by Najdis and indeed most Ajamis too. When explaining their view towards the use of the Ghawa Syndrome verb structure, the words 'correct', 'right', 'wrong', 'Kuwaiti' and 'non-Kuwaiti' were often used. Some Ajamis truly believed that using the CiCC- form is 'embarrassing'. Two young Ajami sisters agreed that 'you feel like the person in front of you is going to laugh when you say verbs like [sim\{at], but they don't - out of respect'. Female Ajamis and Najdis seem to be the most concerned with prestige and how their dialect reflects on their status in society.

\section{Conclusion}

This study investigated the Ghawa Syndrome as it appears in specific verb forms in KA. 48 male and female Kuwaitis participated in this investigation. The informants were from two ethnic backgrounds, one very high on the social scale (Najdi) and the other far below on the social scale (Ajami). Moreover, the informants belonged to three age groups, chosen specifically to fit significant historical events in Kuwait. The recordings where collected in three distinctive methods to insure reliability of the statistics. Spontaneous and non-spontaneous data was obtained from the three recording methods (free talk, picture elicitation, and map reading). The data was analysed in SPSS to find frequency, and measure significance.

This examination investigated the impact of the social factors: ethnicity, age and gender on the realization of the Ghawa Syndrome verb forms, and the impact of these social factors while interrelating with each other. Ethnicity demonstrated a reasonable effect on the realizations of the forms under investigation as it is additionally connected with social and economic prestige. 
From the data, it appears that the Najdis categorically realize the two verb structures (past $3^{\text {rd }}$ person singular feminine and past $3^{\text {rd }}$ person plural) as ICCi- or ICCa-, while Some Ajamis would realize these verb structures as CiCC-. The Najid verb forms, when compared to SA reflects what has been called in the literature as Ghawa Syndrome. However, the literature usually refers to nouns, and this study investigated the same phenomena, yet in verbs.

From the analysis of data, it is clear that the old Ajamis are the most prolific users of this form, and when gender was viewed as an isolated social factor, it was found to be insignificant in the realisation of Ghawa Syndrome verb forms. However, when age and gender interact, it was found that old and middle-aged female Ajamis use the CiCC- verb form significantly more than their male counterparts. The occurrence of the CiCC- verb form in the Ajamis speech could be due to dialect levelling. In an attempt to use the Ghawa Syndrome verb structure (Najdi ICCa- or ICCi-), and the previous knowledge of the SA CaCC- structure (through religious rituals), Ajamis seem to have produced a combination of both. Nonetheless, in this study, not all informants have shown dialect levelling. Nevertheless, due to more dialect contact between Ajamis and Najdis), a significant number of middleaged and young Ajamis use Ghawa Syndrome verb forms (cf. Holes, 1987). While only two ethnic groups have been observed in conducting this study, it would be interesting to investigate other ethnic groups, and their Kuwaiti speech.

Age was, additionally, a huge social factor influencing the realization of the investigated Najdi verb forms. Age has demonstrated a reasonable connection with language and prestige. The social and financial development of Kuwait has demonstrated a clear impact on the interpersonal organization of Kuwaiti Ajamis. The old Ajamis safeguarded an affectionate system which depended on kinfolk and neighbour connections, and along these lines, they kept up their linguistic contrasts. The middle age group kept up family ties, yet additionally demonstrated more contact with different gatherings in the general public, and subsequently bit by bit changed their vernacular. The youthful gathering, then again, showed more mix with the more extensive society, and a weaker connection to family and neighbours. This has influenced their accent, and demonstrated a solid inclination towards vernacular levelling (cf. Trudgill 1986).

Supported by historical events in Kuwait, Najdis in Kuwait consider themselves to be the 'real' Kuwaitis, and hence their dialect is observed as the 'real' Kuwaiti dialect. Najdi participant did not hesitate to say that their dialectal features reflect their social identity and community belonging. Consequently, most Najdis would not hesitate to 'correct' their kids' use of non-Najdi variants if they occurred. On the other side of the scale, most young Ajamis believe that people should 'correct' a family or friend to avoid the embarrassment occurring from 'wrong' realizations. Kuwait has passed the time when Ajamis were labelled as 'foreigners', however, distance is still evident. While language is no longer a barrier of acceptance in the Kuwaiti society, the perfection of this acquisition is the aim of Ajamis. It is believed that dialect transformation is, in fact, a social transformation in the relationship and connection between the two ethnicities.

\section{References:}

1. Abu Haidar, F. (1989) 'Are Iraqi women more prestige conscious than men? Sex differences in Baghdadi Arabic', Language in Society, 18, pp. 471-481.

2. Abu-Hakima, A. M. (1983) The Modern History of Kuwait. London: Luzac \& Co.

3. Al-Wer, E. (1991) Phonological Variation in the Speech of Women from Three Urban Areas in Jordan. $\mathrm{PhD}$ thesis. University of Essex.

4. Al-Wer, E. (2003) 'Education New dialect formation: The focusing of -kum in Amman. in Britain, D. And Cheshire, J. (eds), Social Dialectology. Amsterdam: J. Benjamins, pp. 59-67.

5. Al-Wer, E. (2004) 'Variability reproduced: A variationist View of the [ð़] / [ḍ] opposition in modern Arabic dialects'. In Versteegh, K., Haak, M. and R. Jong (ed), Approaches to Arabic Dialectology. Amsterdam: Brill Academic Publishers. Pp. 21-31. 
6. Al-Wer, E. (2005) ' The formation of the dialect of Amman: from chaos to order'. In C. Miller, D. Caubet, J. Watson \& E. Al-Wer (eds), Arabic in the City: Issues in Dialect Contact and Language Variation, 5576. London: Routledge-Curzon.

7. Al-Wer, E. (2007) 'The formation of the dialect of Amman: from chaos to order', in Miller, C., Caubet, D., Watson, J. and Al-Wer, E.(eds) Arabic in The City: Issues in Dialect Contact and Language Variation. London: Routledge. Pp.55-76.

8. Al-Wer, E. (2008). Variation. In K. Versteegh, M. Eid, A. Elgibali, M. Woidich, \& A. Zaborski, (Eds.), Encyclopedia of Arabic Laguage \& Linguistics, pp.627-37. Leiden: Brill.

9. Anderson, A. H., Bader, M., Bard, E., Boyle, E., Docherty, G., Garrod, S., Isord, S., Kowtko, J., Mcallistar, J., Miller, J., Sotillo, C., Thompson, H. and Weinrt, R. (1991) 'The HCRC map task corpus', Language and Speech, 34, (4), pp. 351-66.

10. Bassiouney, R. (2009) Arabic Sociolinguistics. U.K.: Edinburgh University Press.

11. Bortoni-Ricardo, S. M. (1985) The Urbanization of Rural Dialect Speakers: A Sociolinguistic Study in Brazil. Cambridge: Cambridge University Press.

12. Brown, P. (2000) Speakers, Listeners and Communication: Exploration in Discourse Analysis. Cambridge: Cambridge University Press.

13. Delattre, P. (1964): 'Change as a correlate of the vowel-consonant distinction', Studia Lingüistica, XVIII, 12-25. Edinburgh University Press

14. Eckert, P. (2000) Linguistic Variation as Social Practice. Oxford: Blackwell.

15. Foulkes, P. and Docherty, G. (2006) 'The Social Life of Phonetics and Phonology', Journal of Phonetics, 34, (4), pp. 409-438.

16. Giles, H. (1991) Language, Society and the Elderly. Oxford: Blackwell.

17. Hassan, B. (2009) Ideology, identity, and linguistic capital: A sociolinguistic investigation of language shift among the Ajam of Kuwait. Ph.D. Thesis, University of Essex.

18. Holes, C. (1983) "Bahraini dialects: sectarian differences and the sedentary/nomadic split", ZAL, 10, pp. 7-38.

19. Holes, C. (1987) Language Variation and Change in a Modernising Arab State: the case of Bahrain. London and New York: Kegan Paul International.

20. Holes, C. (2015) Modern Arabic: Structures, Functions and Varieties. London: Brill.

21. Holes, C. (2018) Kuwaiti Arabic. In: Encyclopaedia of Arabic Language and Linguistics, Managing Editors Online Edition: Lutz Edzard, Rudolf de Jong.

22. Ibrahim, M. (1986) 'Standard and prestigious language: A problem in Arabic sociolinguistics', Anthropological Linguistics, 28, pp. 115-126.

23. Johnstone, T. M. (1967) Eastren Arabic Dialect Studies. Oxford: Oxford University Press.

24. Kanovsky, E. (1976) The Economic Development of Jordan. Edison, U.S.: Transaction Publishers.

25. Labov, W. (1966) The Social Stratification of English in New York City. Washington DC: Center for Applied Linguistics.

26. Mazraani, N. (1997) Aspects of Language Variation in Arabic Political Speech-Making. Surrey: Curzon Press.

27. Miller, J. E. and Weirt, R. (1998) Spontaneous Spoken Language: Syntax and Discourse. Oxford: Oxford University Press. 
28. Ohannessian, S., Ferguson, C. A. and Polom, E. C. (1975) Language surveys in developing nations: papers and reports on sociolinguistic surveys. Washington D. C.: Center for Applied Linguistics

29. Sidnell, J. (1999) 'Competence', Journal of Linguistic Anthropology, 9, (1-2), pp. 38-41.

30. Suleiman, Y. (2003). The Arabic Language and National Identity. Edinburgh: Edinburgh University Press.

31. Taglimonte, S. (2006) Analysing Sociolinguistic Variation. Cambridge: Cambridge University Press.

32. Taqi, H. (2016) Two Ethnicities, Three Generations: Phonological Variation and Change in Kuwait. Thesis, Newcastle University, 2010. Germany: Lap Lambert Academic Publishing.

33. Trudgill, P. (1986) Dialects in Contact. Oxford: Blackwell.

34. Trudgill, P. (2000) Sociolinguistics: An Introduction to Language and Society. 4th England: Penguin Publishing.

35. Trudgill, P. (2002) Sociolinguistic Variation and Change. New York: Georgetown University Press.

36. Trudgill, P. (2009) 'Contact and sociolinguistic typology', in R. Hickey (ed.), Handbook of language contact. Oxford: Blackwell.

37. http://www.worldometers.info/world-population/kuwait-population/. Viewed $20^{\text {th }}$ January 2018.

\section{Author' biography with Photo}

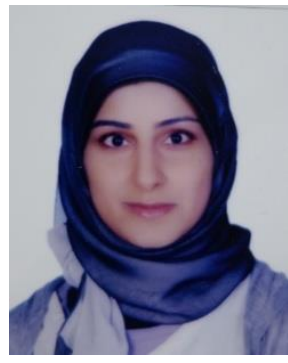

Hanan A. Taqi holds a Ph.D. in Phonology from Newcastle University - UK. As a holder of an Educational and Applied Linguistics degree, she has focused her publications on the area of phonology, EFL, language learning and sociolinguistics. Her area of expertise in the field of sounds, and interest in the psychology associated with sound production has combined to form a passion for the concept of Public Speaking. 